\title{
Therapeutic effects of ulinastatin on postoperative complications and cognitive function in elderly patients with esophageal cancer after thoracic laparoscopic surgery
}

\author{
Peng Yuan1, Yanli Wang ${ }^{2}$, Chunlai Jin, Daling Wang ${ }^{1 *}$ \\ ${ }^{1}$ Department of Thoracic Surgery, First People's Hospital, Jinan, ${ }^{2}$ Department of Geriatrics, Fifth People's Hospital, Qingdao, \\ China \\ *For correspondence: Email: zaitofk0816@163.com
}

Sent for review: 19 March 2021

Revised accepted: 28 May 2021

\begin{abstract}
Purpose: To investigate the therapeutic effect of ulinastatin on postoperative complications and cognitive function in elderly patients with esophageal cancer after thoracic laparoscopic surgery.

Methods: A total of 100 elderly in-patients with esophageal cancer who had undergone thoracic laparoscopic surgery from April 2019 to December 2020 were selected and randomly assigned to control and study groups. Patients in control group received conventional treatment, while those in the study group were administered ulinastatin. The two groups were compared with respect to response, incidence of postoperative complications, Mini-Mental State Examination (MMSE) cognitive function score, Barthel Index (BI) scores; preoperative, intraoperative, 12-h and 24-h post-surgery levels of IL-1 $\beta$ and IL-6; levels of $\mathrm{CD}^{+}, C D 4^{+}$and $C D 8^{+}$, as well as duration of surgery and waking time.

Results: Response, MMSE score, BI index, and levels of $C D 3^{+}, C D 4^{+}$and $C D 8^{+}$in the study group were significantly higher than those in the control group $(p<0.05)$. Incidence of postoperative complications, and expression levels of $I L-1 \beta$ and $I L-612 h$ and $24 h$ after surgery in the study group were lower than the corresponding control levels $(p<0.05)$. There were no significant differences in duration of operation and waking time between the two groups $(p>0.05)$.

Conclusion: Ulinastatin significantly reduces postoperative complications, and also improves cognitive function in elderly patients with esophageal cancer after thoracic laparoscopic surgery. This finding is of great significance in the treatment of these patients.
\end{abstract}

Keywords: Ulinastatin, Aged patients, Esophageal cancer, Thoracic laparoscopy, Cognitive function, Inflammatory cytokines

This is an Open Access article that uses a fund-ing model which does not charge readers or their institutions for access and distributed under the terms of the Creative Commons Attribution License (http://creativecommons.org/licenses/by/4.0) and the Budapest Open Access Initiative (http://www.budapestopenaccessinitiative.org/read), which permit unrestricted use, distribution, and reproduction in any medium, provided the original work is properly credited.

Tropical Journal of Pharmaceutical Research is indexed by Science Citation Index (SciSearch), Scopus, International Pharmaceutical Abstract, Chemical Abstracts, Embase, Index Copernicus, EBSCO, African Index Medicus, JournalSeek, Journal Citation Reports/Science Edition, Directory of Open Access Journals (DOAJ), African Journal Online, Bioline International, Open-J-Gate and Pharmacy Abstracts

\section{INTRODUCTION}

Esophageal cancer is a disease of the digestive system with increasing incidence, mostly among the elderly population. Currently, the treatment of esophageal cancer is mainly based on conventional and minimally invasive esophagectomy (MIE) which is a simple operation associated with low trauma and rapid recovery [1-3]. Since the cardiopulmonary function of elderly patients gradually decreases 
with age, this decline may affect prognosis in the treatment of elderly patients. In addition, postsurgery complications such as respiratory depression and surgical wound infection are not conducive for recovery [4-6].

Clinical trials have found that the cognitive function of elderly patients administered MIE are affected to some extent. For instance, the patients may have cognitive impairment, cognitive dysfunction and other manifestations, which negatively impact on the quality of life and impose psychological and economic pressure on them and their families [7]. Ulinastatin is an antiinflammatory drug which is clinically beneficial in various types of pancreatitis [8].

To investigate the effectiveness of ulinastatin in elderly patients with esophageal cancer, and assess its effects on postoperative complications and cognitive function after thoracic laparoscopic surgery, this study used elderly patients with esophageal cancer after thoracic laparoscopic surgery, as subjects. The response, incidence of complications, cognitive function, inflammatory factors and immune function were compared between subjects who received conventional treatment and those who were given ulinastatin in addition to conventional therapy.

\section{METHODS}

\section{General profile of patients}

A total of 100 elderly in-patients with esophageal cancer who had received thoracic laparoscopic surgery from April 2019 to December 2020 were selected and randomly divided into control group and a study group. Patients in the control group were aged 63 - 76 years, while those in the study group were aged 65 to 75 years. There were no significant differences in baseline information between the two groups, as shown in Table 1. This study was approved by Medical Science Research Ethics Committee of Jinan City People's Hospital (approved no. 2019 (CFS83)12 and followed international guidelines for human studies [9].

\section{Inclusion/exclusion criteria}

\section{Inclusion criteria}

The following categories of patients were included in the study: those who had the clinical features of esophageal cancer and were administered MIE in our hospital; patients aged 60 or below, with no major organ disease, and patients who had no history of drug allergy, drug abuse or addiction to smoking or alcohol.

\section{Exclusion criteria}

Patients with chronic obstructive pulmonary disease, mental disorders, and those who were not ready to cooperate in the study, were excluded. Moreover, patients who underwent a major gastric surgery were excluded.

The study was approved by the ethics committee of our hospital. All patients voluntarily participated in the study, and each patient submitted a signed informed consent form.

\section{Treatments}

Patients in the control group received routine operation diet therapy, namely abstinence from food and drink $8 \mathrm{~h}$ before surgery, and routine physical examination, and venous access was set before surgery.

Table 1: General patient information

\begin{tabular}{lcccc}
\hline Group & Study group & Control group & $\mathbf{t} / \mathbf{X}^{\mathbf{2}}$ & $\boldsymbol{P}$-value \\
\hline Gender & $28 / 22$ & $30 / 20$ & 0.16 & 0.69 \\
(male/female) & $68.83 \pm 5.22$ & $68.95 \pm 5.38$ & 0.11 & 0.91 \\
Age (years) & $164.22 \pm 6.61$ & $164.30 \pm 6.99$ & 0.06 & 0.95 \\
Height (cm) & $68.81 \pm 7.30$ & $68.11 \pm 7.47$ & 0.47 & 0.64 \\
Weight (kg) & $2.00 \pm 0.36$ & $2.08 \pm 0.43$ & 1.01 & 0.32 \\
$\begin{array}{l}\text { Medical history } \\
\text { (months) }\end{array}$ & $11.69 \pm 2.57$ & $11.20 \pm 2.66$ & 0.94 & 0.35 \\
$\begin{array}{l}\text { Smoking history } \\
\text { (years) }\end{array}$ & $15.94 \pm 3.03$ & $15.85 \pm 3.79$ & 0.13 & 0.90 \\
$\begin{array}{l}\text { Drinking history } \\
\text { (years) }\end{array}$ & 16 & 14 & & \\
Hypertension & 10 & 13 & 0.19 & 0.66 \\
$\begin{array}{l}\text { (case) } \\
\text { Diabetes (case) }\end{array}$ & 8 & 10 & 0.51 & 0.48 \\
Hyperlipidemia $(\mathrm{n})$ & & & 0.27 & 0.60 \\
\hline
\end{tabular}


They were given midazolam (Jiangsu NHWA Pharmaceutical Co. Ltd, SFDA approval no. $\mathrm{H} 10980026)$ at a dose of $0.04 \mathrm{mg} / \mathrm{kg}$; cisatracurium (Jiangsu Ruiheng Pharmaceutical Co. Ltd; SFDA approval no. H20060869, specifications: $10 \mathrm{mg}$ ) at a dose of $0.10 \mathrm{mg} / \mathrm{kg}$, anesthesia with propofol (Sichuan Guorui Pharmaceutical Co. Ltd, SFDA approval no. H20040079; specification: $10 \mathrm{~mL}: 0.1 \mathrm{~g}$ ) at a dose of $2 \mathrm{mg} / \mathrm{kg}$, and intravenous remifentanil (Jiangsu NHWA Pharmaceutical Co. Ltd, SFDA approval no. $\mathrm{H} 20143314$; specification: $1 \mathrm{mg}$ ) at a rate of $4 \mathrm{ng} / \mathrm{min} / \mathrm{kg}$, followed $3 \mathrm{~min}$ later by endotracheal intubation. Sevoflurane anesthesia (1 - $3 \%$; Shanghai Future Industry Co. Ltd, Batch no. 1612540CAS; specification: $120 \mathrm{~mL}$ ) was maintained intraoperatively. Target-controlled infusion of remifentanil was kept at $3 \mathrm{ng} / \mathrm{min} / \mathrm{kg}$, and the administration was stopped after the operation.

In addition to the treatment given to the control group, the study group received one-time intravenous injection of ulinastatin (Guangdong Tianpu Biochemical Pharmaceutical Co. Ltd, SFDA approval no. H19990133) at a dose of $10000 \mathrm{U} / \mathrm{kg}$ within 20 min before the operation. Intravenous injection of ulinastatin (5000 U/kg) was given at 24,48 and $72 \mathrm{~h}$ after surgery.

\section{Study indices}

The study made comparison between the two groups with respect to response, incidence of postoperative complications, MMSE score, $\mathrm{BI}$, preoperative, intraoperative, $12 \mathrm{~h}$ postoperation and $24 \mathrm{~h}$ post-operation levels of IL-1 $\beta$ and IL-6; levels of CD3+, CD4+ and CD8+, as well as duration of operation and waking time.

When no adverse reaction occurred in the patients, and the clinical manifestations basically disappeared, the treatment outcome was classified as complete response. If minor adverse reactions occurred and then disappeared without drug intervention, the outcome was classified as partial response. However, if patients presented severe adverse reactions, with persistence of clinical manifestations, the treatment outcome was considered no response.

Response rate $=$ (complete response+ partial response)/Total ${ }^{*} 100 \%$.

The MMSE cognitive function rating scale has a total score of 30 points, and contains indicators such as time orientation, place orientation, immediate memory, attention, calculation, delayed memory, and other indicators. Respondents with junior high school education or beyond, were assessed to be normal if they scored more than 24 points. Those who just had primary school education were considered normal if they scored above 20 points, while patients who had no primary school education were expected to score at least 17 points.

In the $\mathrm{BI}$, the maximum score is usually 100 points. This score means that the patient does not need care from others, and can live on their own. Scores of 61 - 99 indicate that they need occasional care from others, and can basically take care of themselves. On the other hand, scores of 41 - 60 show that they need to be attended to most of the time, and that they are almost unable to self-care. A score below 40 means complete disability and the need for intensive care. In this study, the $\mathrm{Bl}$ scores of patients in the two groups were compared.

Immune function indicators were also compared. The higher the levels of CD3+, CD4+ and CD8+ in patients, the stronger the immune function.

\section{Statistical analysis}

Measurement data are expressed as mean \pm SD, and were compared using $t$-test. Enumeration data are presented as numbers and percentages [n (\%)], and were compared with $\mathrm{X}^{2}$ test. The SPSS 20.0 statistical software was used for data processing, while GraphPad Prism 7 (GraphPad Software, San Diego, USA) was used for graphics. Differences were assumed statistically significant when $p<0.05$.

\section{RESULTS}

\section{Treatment response}

In the study group, there were 35 cases of complete response, 11 cases of partial response, and 4 cases with no response, with an overall response rate of $92 \%$. In the control group, there were 21 cases of remarkable response, 14 cases of partial response, and 15 cases of no response, with overall response of $70 \%$, which was significantly lower than the study group ( $p$ $=0.005$ ) as shown in Table 2 .

\section{Incidence of complications}

In the study group, there was 1 patient with respiratory tract infection and 4 patients with thoracic drainage, with the adverse reaction rate of $10 \%$. In the control group, there was 1 patient with pneumonia, 3 patients with respiratory tract infection, and 9 patients with thoracic drainage, 
with the adverse reaction rate $26 \%$, which was significantly higher than the study group $(p=$ 0.037). As shown in Table 3.

\section{MMSE and BI scores}

In the study group, MMSE and $\mathrm{BI}$ scores were $27.79 \pm 3.06$ and $59.93 \pm 10.2$ ), respectively. In the control group, the MMSE and $\mathrm{BI}$ scores were $20.15 \pm 2.59$ and $53.08 \pm 8.84$, respectively. MMSE and $\mathrm{BI}$ scores in the study group were significantly higher than the corresponding scores in the control group $(p<0.05)$. As shown in Figure 1.

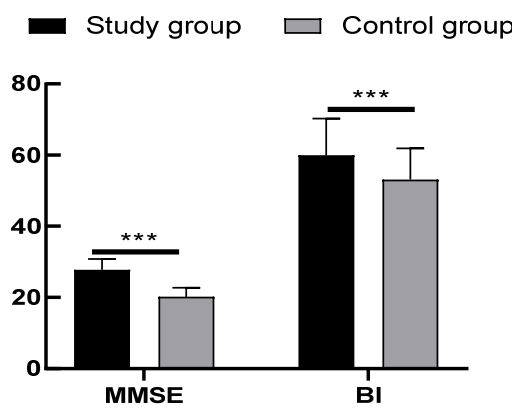

Figure 1: Comparison of MMSE score and $\mathrm{BI} .{ }^{* * *} P<$ 0.001

Expression levels of IL-1 $\beta$ and IL-6 at preoperative and intraoperative stages, and 12 and $24 h$ after surgery

The results are shown in Figure 2. There was no significant difference in the preoperative expression levels of $\mathrm{IL}-1 \beta$ in the study group $27.99 \pm 2.61 \mathrm{ng} / \mathrm{L}$ and in the control group 28.23 $\pm 2.87 \mathrm{ng} / \mathrm{L}(p=0.66$. The intraoperative expression level of IL-1 $\beta$ in the study group was
$44.31 \pm 3.95 \mathrm{ng} / \mathrm{L}$, which was not significantly different from that in the control group (45.00 \pm $4.01 \mathrm{ng} / \mathrm{L}, p=0.39$ ). The expression level of IL$1 \beta$ in the study group $(38.22 \pm 3.57 \mathrm{ng} / \mathrm{L})$ at $12 \mathrm{~h}$ after surgery was significantly lower than that in the control group $(44.64 \pm 3.96 \mathrm{ng} / \mathrm{L}, p<0.001)$. At $24 \mathrm{~h}$ after surgery, the expression level of IL$1 \beta$ in the study group $(32.28 \pm 3.04 \mathrm{ng} / \mathrm{L})$ was markedly lower than that in the control group $(40.19 \pm 3.63 \mathrm{ng} / \mathrm{L}, p<0.001)$. The preoperative expression level of IL- 6 in the study group (16.85 $\pm 2.17) \mathrm{ng} / \mathrm{L}$ was comparable to that in the control group (16.59 $\pm 2.23, p=0.56)$. Intraoperative expression level of IL-6 in the study group $(50.26 \pm 4.96 \mathrm{ng} / \mathrm{L})$ was similar to that in the control group $(50.49 \pm 5.0 \mathrm{ng} / \mathrm{L}, p=$ 0.82). In contrast, at $12 \mathrm{~h}$ after surgery, the expression level of IL-6 in the study group (41.92 $\pm 4.03) \mathrm{ng} / \mathrm{L}$ was significantly lower than that in the control group $(48.73 \pm 4.55 \mathrm{ng} / \mathrm{L}, p<0.001)$. The expression level of IL-6 in the study group $(35.57 \pm 3.66 \mathrm{ng} / \mathrm{L}) 24 \mathrm{~h}$ after operation was markedly lower than that in the control group (44.15 $\pm 4.20 \mathrm{ng} / \mathrm{L}, p<0.001)$.
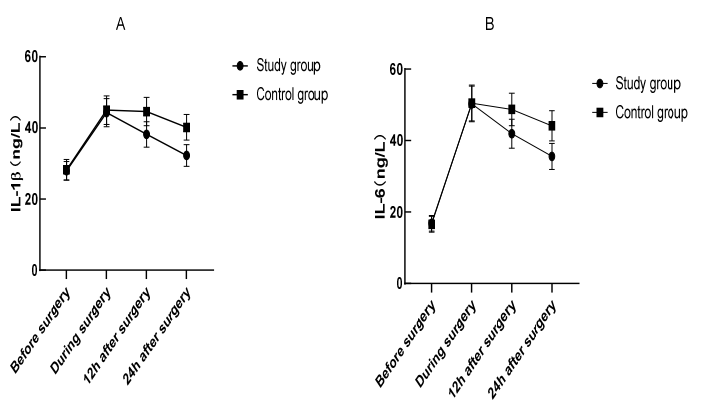

Figure 2: Comparison of the expression levels of $(A)$ $\mathrm{IL}-1 \beta$ and (B) IL-6 at preoperative and intraoperative stages, and 12 and $24 \mathrm{~h}$ after surgery

Table 2: Comparison of the treatment response between the two groups $\{(\mathrm{n}(\%)\}$

\begin{tabular}{lcccc}
\hline Variable & $\begin{array}{c}\text { Complete } \\
\text { response }\end{array}$ & $\begin{array}{c}\text { Partial } \\
\text { response }\end{array}$ & No response & Response rate \\
\hline Study group $(n=50)$ & 35 & 11 & 4 & $46(92 \%)$ \\
Control group $(n=50)$ & 21 & 14 & 15 & $35(70 \%)$ \\
$\chi^{2}$ & & & & 7.826 \\
P-value & & & & 0.005 \\
\hline
\end{tabular}

Table 3: Comparison of the incidence of complications between the two groups $\{(\mathrm{n}(\%)\}$

\begin{tabular}{lcccc}
\hline Variable & Pneumonia & $\begin{array}{c}\text { Respiratory tract } \\
\text { infection }\end{array}$ & $\begin{array}{c}\text { Thoracic } \\
\text { drainage }\end{array}$ & $\begin{array}{c}\text { Adverse } \\
\text { reaction rate }\end{array}$ \\
\hline Study group $(n=50)$ & 0 & 1 & 4 & $5(10 \%)$ \\
Control group $(n=50)$ & 1 & 3 & 9 & $13(26 \%)$ \\
$\chi^{2}$ & & & 4.336 \\
$P$-value & & & & 0.037 \\
\hline
\end{tabular}


Table 4: Comparison of expression levels of CD3+, CD4+ and CD8+ $\left(\mu \mathrm{L}^{-1}\right.$, mean $\left.\pm \mathrm{SD}\right)$

\begin{tabular}{lccc}
\hline Group & CD3 $^{+}$ & CD4 $^{+}$ & CD8 $^{+}$ \\
\hline Study group & $886.32 \pm 108.76$ & $502.02 \pm 89.72$ & $496.17 \pm 89.90$ \\
Control group & $742.59 \pm 99.36$ & $365.27 \pm 73.85$ & $338.70 \pm 74.71$ \\
$T$ & 6.90 & 8.32 & 9.53 \\
$P$-value & $<0.001$ & $<0.001$ & $<0.001$ \\
\hline
\end{tabular}

\section{Expression levels of CD3+, CD4+ and CD8+}

Table 4 shows that the study group was superior to the control group in terms of levels of CD3+, $\mathrm{CD} 4+$ and $\mathrm{CD} 8+(p<0.05)$.

\section{Operation duration and waking time}

As shown in Table 5, there were significant differences in duration of operation and waking time between the two groups $(p>0.05)$.

Table 5: Duration of operation and waking time

\begin{tabular}{lcc}
\hline Group & $\begin{array}{c}\text { Operation } \\
\text { duration }(\mathbf{m i n})\end{array}$ & $\begin{array}{c}\text { Waking time } \\
(\mathbf{m i n})\end{array}$ \\
\hline Study group & $54.41 \pm 8.84$ & $23.06 \pm 2.21$ \\
Control group & $55.07 \pm 8.92$ & $23.76 \pm 2.55$ \\
$T$ & 0.37 & 1.45 \\
$P$-value & 0.71 & 0.15 \\
\hline
\end{tabular}

\section{DISCUSSION}

Elderly patients with esophageal cancer tend to have memory loss and postoperative cognitive dysfunction which considerably affect their daily lives. It has been reported that MIE is the mainstay in the treatment of esophageal cancer, and it is a simple operation associated with low trauma and rapid recovery [10-12]. However, since the body functions of elderly patients gradually decrease with age, especially immune function, respiratory function and circulation function, they may suffer postoperative complications such as pneumonia, respiratory infections and chest drainage, all of which will impair recovery, and affect other physical functions [13-14].

Previous reports show that ulinastatin reduced the incidence of postoperative complications in elderly patients with esophageal cancer [15]. A regularly-used anti-inflammatory drug in clinics, ulinastatin is composed of glycoproteins and protease inhibitors, and it is widely used for patients with certain types of pancreatitis [16]. In this study, elderly in-patients with esophageal cancer who had received thoracic laparoscopic surgery were used as subjects for comparison of the effects of conventional treatment and additional ulinastatin treatment on percentage response, incidence of complications, cognitive function, inflammatory factors and immune function. It was found that the percentage response, MMSE score, $\mathrm{BI}$ index, and expression levels of CD3+, CD4+ and CD8+ in the study group treated with ulinastatin were significantly higher than those in the control group given conventional treatment. These results suggest that ulinastatin is important for improving treatment efficiency and eliminating clinical manifestations in patients with esophageal cancer.

Decline in patients' cognitive function after surgery may be induced by physiological and psychological factors. From a physiological perspective, anesthesia drugs and other drugs used during surgery may have a certain influence on the cognitive function of the patient [17]. With respect to psychological factors, the patients may be unable to face their illness, resulting in depression and other negative emotions. Longterm negative emotions may lead to decline in cognition which negatively impacts on ability to cope with daily life or loss of capacity for selfcare, thereby increasing pressure on their families.

The results of this study showed substantial improvements in the cognitive function and selfcare ability of patients treated with ulinastatin, indicating that ulinastatin markedly improved the cognitive function of elderly patients with esophageal cancer. In addition, ulinastatin increased the expression levels of CD3+, CD4+ and $\mathrm{CD} 8+$, improved immune function and eliminated complications in the course of treatment.

Furthermore, the incidence of postoperative complications and the expression levels of IL-1 $\beta$ and IL-6 12 and $24 \mathrm{~h}$ after surgery were significantly lower in the study group, which demonstrated that ulinastatin significantly reduced the incidence of postoperative complications in patients with esophageal cancer. It markedly lowered the levels of postoperative inflammatory cytokines, thereby alleviating inflammatory reactions in patients. Moreover, no statistical differences in the expression levels of IL-1 $\beta$ and IL- 6 before and during operation, duration of operation and waking time were observed between the two groups. Waking time is related to the usage and dosage of anesthetic drugs, suggesting that 
ulinastatin has little impact on anesthetic drugs in humans. It has been reported that ulinastatin was efficient improving the cognitive level of patients with esophageal cancer after MIE, and that it significantly reduced the incidence of complications [18]. The results of the present study are consistent with these findings, thereby indicating their scientific reliability.

\section{CONCLUSION}

Ulinastatin has the advantage of significantly reducing postoperative complications in elderly patients with esophageal cancer, improving their cognitive function and immune function, and reducing the expression levels of inflammatory cytokines. Therefore, ulinastatin is of great benefit in the treatment of elderly patients with esophageal cancer.

\section{DECLARATIONS}

\section{Conflict of interest}

No conflict of interest is associated with this work.

\section{Contribution of authors}

We declare that this work was done by the authors named in this article and all liabilities pertaining to claims relating to the content of this article will be borne by the authors.

\section{Open Access}

This is an Open Access article that uses a funding model which does not charge readers or their institutions for access and distributed under the terms of the Creative Commons Attribution License (http://creativecommons.org/licenses/by/ 4.0) and the Budapest Open Access Initiative (http://www.budapestopenaccessinitiative.org/rea d), which permit unrestricted use, distribution, and reproduction in any medium, provided the original work is properly credited.

\section{REFERENCES}

1. Murthy RA, Clarke NS, Kernstine KH Sr. Minimally Invasive and Robotic Esophagectomy: A Review. Innovations (Phila) 2018; 13(6): 391-403.

2. van der Sluis $P C$, Schizas $D$, Liakakos $T$, van Hillegersberg R. Minimally Invasive Esophagectomy. Dig Surg 2020; 37(2): 93-100.

3. Yibulayin $W$, Abulizi S, $L v H$, Sun W. Minimally invasive oesophagectomy versus open esophagectomy for resectable esophageal cancer: a meta-analysis. World J Surg Oncol 2016; 14(1): 304.

4. Li J, Shen Y, Tan L, Feng M, Wang $H$, Xi Y, Wang Q. Is minimally invasive esophagectomy beneficial to elderly patients with esophageal cancer? Surg Endosc 2015; 29(4): 925-30.

5. Uchihara T, Yoshida N, Baba Y, Nakashima Y, Kimura Y, Saeki H, Takeno S, Sadanaga N, Ikebe M, Morita M, et al. Esophageal Position Affects Short-Term Outcomes After Minimally Invasive Esophagectomy: A Retrospective Multicenter Study. World J Surg 2020; 44(3): 831-837.

6. Day RW, Jaroszewski D, Chang $Y H$, Ross HJ, Paripati $H$, Ashman JB, Rule WG, Harold KL. Incidence and impact of postoperative atrial fibrillation after minimally invasive esophagectomy. Dis Esophagus 2016; 29(6): 583-8.

7. Taioli E, Schwartz RM, Lieberman-Cribbin W, Moskowitz $G$, van Gerwen M, Flores R. Quality of Life after Open or Minimally Invasive Esophagectomy in Patients with Esophageal Cancer-A Systematic Review. Semin Thorac Cardiovasc Surg 2017; 29(3): 377-390.

8. Wang G, Liu Y, Zhou SF, Qiu P, Xu L, Wen P, Wen J, Xiao $X$. Effect of Somatostatin, Ulinastatin and Gabexate on the Treatment of Severe Acute Pancreatitis. Am J Med Sci 2016; 351(5): 506-12.

9. Department of Health, Education, and Welfare; National Commission for the Protection of Human Subjects of Biomedical and Behavioral Research. The Belmont Report. Ethical principles and guidelines for the protection of human subjects of research. J Am Coll Dent 2014; 81(3): 4-13.

10. Bollschweiler E, Plum P, Mönig SP, Hölscher AH. Current and future treatment options for esophageal cancer in the elderly. Expert Opin Pharmacother 2017; 18(10): 1001-1010.

11. Nakashima $Y$, Saeki $H$, Nakanishi $R$, Sugiyama $M$, Kurashige J, Oki E, Maehara Y. Assessment of Sarcopenia as a Predictor of Poor Outcomes After Esophagectomy in Elderly Patients With Esophageal Cancer. Ann Surg 2018; 267(6): 1100-1104.

12. Bernardi D, Asti E, Aiolfi A, Bonitta G, Luporini A, Bonavina L. Outcome of Trimodal Therapy in Elderly Patients with Esophageal Cancer: Prognostic Value of the Charlson Comorbidity Index. Anticancer Res 2018; 38(3): 1815-1820.

13. Molena $D$, Stem M, Blackford AL, Lidor AO. Esophageal Cancer Treatment Is Underutilized Among Elderly Patients in the USA. J Gastrointest Surg 2017; 21(1): 126-136.

14. Natori A, Chan BA, Sim HW, Ma L, Yokom DW, Chen E, Liu G, Darling G, Swallow C, Brar S, et al. Outcomes by treatment modality in elderly patients with localized gastric and esophageal cancer. Curr Oncol 2018; 25(6): 366-370.

15. Wang KY, Yang QY, Tang P, Li HX, Zhao HW, Ren XB. Effects of ulinastatin on early postoperative cognitive function after one-lung ventilation surgery in elderly 
patients receiving neoadjuvant chemotherapy. Metab Brain Dis 2017; 32(2): 427-435.

16. Moggia E, Koti R, Belgaumkar AP, Fazio F, Pereira SP, Davidson BR, Gurusamy KS. Pharmacological interventions for acute pancreatitis. Cochrane Database Syst Rev 2017; 4(4): CD011384.

17. Sun $H$, Zhang $G$, Ai B, Zhang $H$, Kong $X$, Lee WT, Zheng $H$, Yan $T$, Sun $L$. A systematic review: comparative analysis of the effects of propofol and sevoflurane on postoperative cognitive function in elderly patients with lung cancer. BMC Cancer 2019; 19(1): 1248.

18. Qiao $Y$, Feng $H$, Zhao $T$, Yan $H$, Zhang $H$, Zhao $X$. Postoperative cognitive dysfunction after inhalational anesthesia in elderly patients undergoing major surgery: the influence of anesthetic technique, cerebral injury and systemic inflammation. BMC Anesthesiol 2015; 15: 154. 